\title{
One-Pot Sulfoxide Synthesis Exploiting a Sulfinyl-Dication Equivalent Generated from a DABSO/Trimethylsilyl Chloride Sequence
}

\author{
Danny C. Lenstra, Vincent Vedovato, Emmanuel Ferrer Flegeau, Jonathan Maydom,
} and Michael C. Willis*

Department of Chemistry, University of Oxford, Chemistry Research Laboratory, Mansfield Road, Oxford, OX1 3TA, United Kingdom

\section{Supporting Information}

ABSTRACT: A one-pot process for the synthesis of unsymmetrical sulfoxides using organometallic nucleophiles is described. Sulfur dioxide, delivered from the surrogate DABSO (DABCO-bis(sulfur dioxide)), acts as the initial electrophile and combines with the first organometallic reagent to generate a sulfinate intermediate. In situ conversion of the sulfinate to a sulfinate silyl ester, using TMS-Cl (trimethylsilyl chloride), generates a second electrophile, allowing addition of a second organometallic reagent. Organolithium or Grignard reagents can be employed, delivering sulfoxides in good to excellent yields.
$\mathrm{T}$ he sulfoxide moiety is a fundamental functional group found in many biologically active molecules. ${ }^{1}$ For example, omeprazole, a gastric acid inhibitor, is listed as an essential medicine by the World Health Organization (Figure $1) .^{2}$ In addition, sulfoxides are used as ligands in organometallic

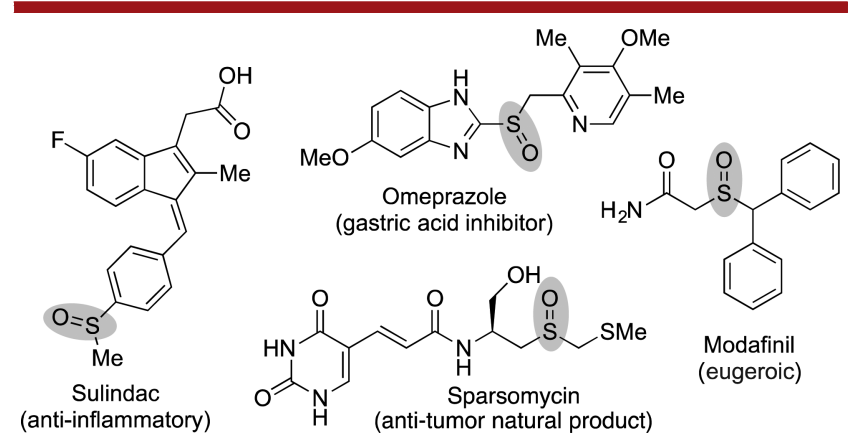

Figure 1. Medicinally relevant sulfoxides.

chemistry, ${ }^{3}$ as organocatalysts, ${ }^{4}$ and as intermediates in a variety of organic transformations, such as the Pummerer and EvansMislow rearrangements, and syn-eliminations. ${ }^{5}$

The most widely employed method for the synthesis of sulfoxides is by oxidation of the corresponding sulfides, for which a wide variety of reagents have been reported (Scheme 1, eq 1). ${ }^{6}$ Drawbacks of these procedures are the requirement for stoichiometric amounts of oxidant, the resultant limited functional group compatibility, and overoxidation to give sulfone products. In addition, the sulfide starting materials are most usually prepared from the corresponding thiols, which are commonly foul smelling. Sulfoxides can also be obtained by nucleophilic displacement on sulfinyl derivatives, such as sulfinamides, and sulfinic esters, with organometallic reagents (Scheme 1, eq 2). ${ }^{7,8}$ However, these starting materials are often
Scheme 1. Common Strategies for the Synthesis of Sulfoxides, DABSO in a Three-Component Sulfone Synthesis, and the Proposed DABSO-Based Sulfoxide Synthesis

Common sulfoxide syntheses:

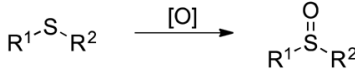

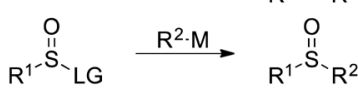

DABSO in sulfone synthesis:

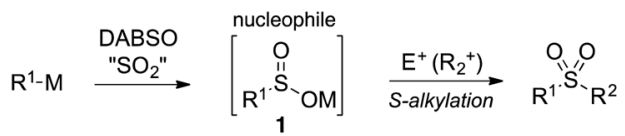

This work. DABSO-based sulfoxide synthesis:

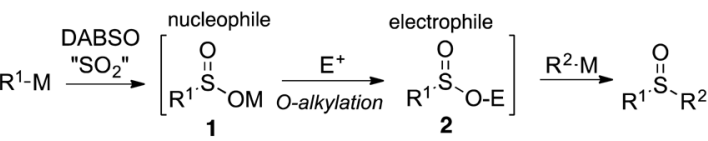

$$
\begin{aligned}
& \mathrm{O}_{\text {DABSO }}^{\mathrm{O}_{\mathrm{N}}} \cdot \mathrm{SO}_{2}
\end{aligned}
$$

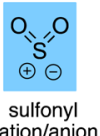

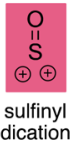

of limited availability. The modification of existing sulfoxides, including the use of palladium-catalyzed protocols, ${ }^{9}$ has also emerged as a useful tool. ${ }^{10}$ Despite these advances, general, efficient methods to access sulfoxides, ideally employing readily available starting materials, remain in demand.

Received: March 11, 2016

Published: April 15, 2016 
We have recently reported a three-component one-pot route to sulfones, ${ }^{11 \mathrm{a}}$ in which an intermediate sulfinate salt (1), generated from an organometallic reagent and the sulfur dioxide surrogate DABSO (DABCO-bis(sulfur dioxide)), ${ }^{12-14}$ undergoes $S$-alkylation to deliver sulfone products (Scheme 1, eq 3 ). In this process, $\mathrm{SO}_{2}$ is effectively functioning as a sulfonyl cation/anion synthon. Following the success of the sulfone chemistry, we wished to develop a related route to sulfoxides, for which the key goals would be to achieve an operationally simple one-pot process, employ readily available substrates, avoid the use of thiols, and allow the preparation of sulfoxides possessing varied substitution patterns.

To achieve these goals, and in particular to access the correct $S$-oxidation state, we would need to employ a reagent, or reagent combination, that reacts as a sulfinyl dication synthon. ${ }^{15}$ We speculated this should be possible if we could engineer a polarity reversal of the key intermediate (relative to our sulfone synthesis), and deliver an electrophilic species, which would allow the addition of a second nucleophilic organometallic reagent (Scheme 1, eq 4). To achieve the desired polarity reversal we focused on the ambidentate nature of the initially formed sulfinate, reasoning that if we could identify a suitable electrophile to favor $O$-alkylation we would generate a sulfinate ester $(\mathbf{1} \rightarrow \mathbf{2}$, Scheme 1 , eq 4$)$. The sulfinate ester would then undergo reaction with a second organometallic reagent, to deliver the desired sulfoxide product. The combination of $\mathrm{SO}_{2}$, delivered from the solid, bench stable surrogate $\mathrm{DABSO}$, and an $\mathrm{O}$-alkylated sulfinate would provide the targeted sulfinyl dication equivalent. This Letter documents the successful realization of this process.

We began our investigation by attempting the synthesis of diaryl sulfoxide $\mathbf{5 a}$, from the combination of the two relevant aryl Grignard reagents, the $\mathrm{SO}_{2}$-surrogate $\mathrm{DABSO}$, and a suitable electrophile, with the identification of the electrophile being the initial challenge. Meerwein's reagent, triethyloxonium tetrafluoroborate, is one of the few examples of a $C$-electrophile reported to react through the oxygen atom of a sulfinate. ${ }^{16}$ Unfortunately, Meerwein's reagent is also known to react with ethereal solvents, in which organometallic reagents are typically stored and used, and as such we considered its use impractical. Inspired by Vogel's silyl sulfinate chemistry, ${ }^{17}$ we surmised that a Si-electrophile should allow the formation of a suitable sulfinate ester. Turks has also recently shown that silyl sulfinate esters, formed using ene chemistry, do combine effectively with Grignard reagents. ${ }^{18}$ In the event, the use of the simplest and most cost-effective silyl reagent, TMS-Cl (trimethylsilyl chloride), proved to be effective. Optimization of the basic process, employing Grignard reagents 3 and 4, DABSO, and TMS-Cl, is shown in Table 1.

Initial reactions quickly established that the main issue with the proposed synthesis of sulfoxide 5a was concomitant formation of the symmetrical sulfoxide 6a (Table 1, entry 1). However, variation of the stoichiometries of the process, including increasing the equivalents of DABSO (entries 1-3), reducing the equivalents of the second Grignard reagent (4, entries 4-7), and then slightly increasing the amount of TMS$\mathrm{Cl}$ (entries 7-8), improved the selectivity of the reaction considerably. Finally, in order to deliver the most practically straightforward process we also reduced the times for each step of the one-pot reaction and were pleased to find that this in turn allowed an increase in the amount of the second Grignard reagent used, meaning that the first Grignard reagent was not used in large excess (entries 9 and 10). The optimized
Table 1. Optimization of the Synthesis of Sulfoxide $5 a^{a}$

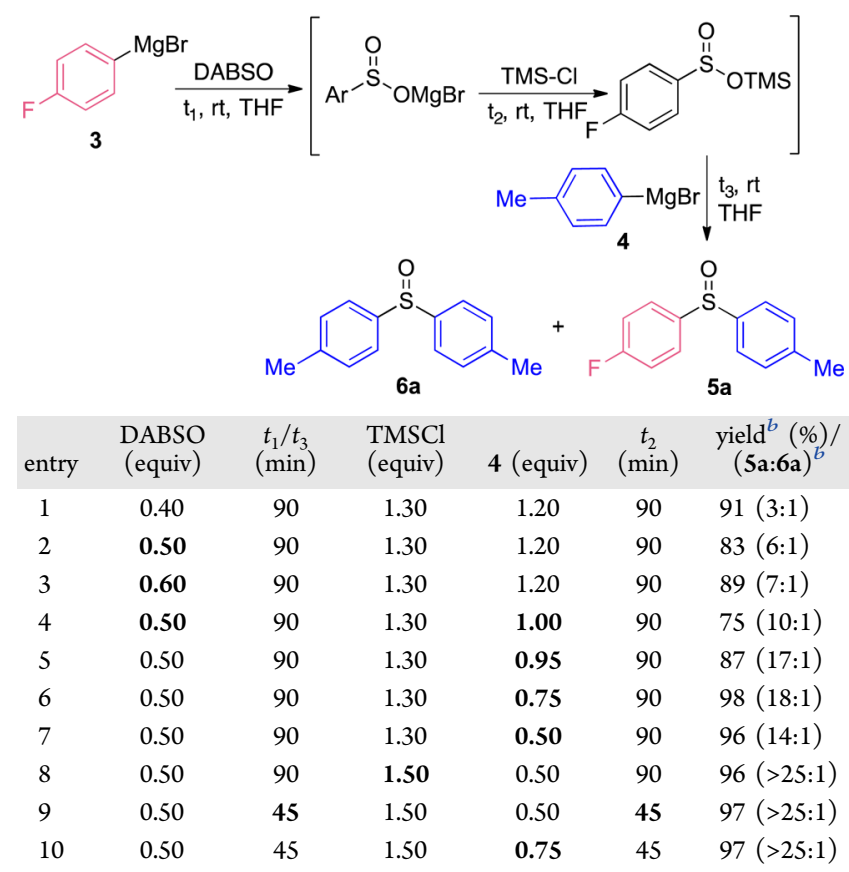

${ }^{a}$ Reaction conditions: 3 (1.0 equiv) and as in table. ${ }^{b}$ Isolated yields. Ratio of 5a:6a determined by ${ }^{1} \mathrm{H}$ NMR spectroscopy.

conditions involved all steps of the process being performed at room temperature, with only a 45 min delay between each stage of the reaction.

With the optimized conditions in hand, we set out to explore the scope of the reaction (Scheme 2). A diverse set of commercially available and in situ generated Grignard reagents were used to synthesize a variety of sulfoxides. We were pleased to find that aromatic Grignard reagents bearing electrondonating, -neutral, and -withdrawing groups could be combined, to afford unsymmetrical diaryl sulfoxides in good yields $(\mathbf{5 a}-\mathbf{d})$. The initial addition of an aryl Grignard reagent could be partnered effectively with primary (5e), secondary $(\mathbf{5 f}, \mathbf{g})$, and tertiary alkyl Grignard reagents $(\mathbf{5 h})$ to deliver mixed arylalkyl sulfoxides.

The order of addition of the organometallic reagents could also be reversed, with a range of primary, secondary alkyl, and benzylic Grignard reagents partnering effectively with the secondary addition of aryl reagents, to deliver good yields of the targeted sulfoxides $(\mathbf{5 i}-\mathbf{n})$. The combination of two different alkyl Grignard reagents was also effective (5o), as were allyl/ aryl (5p) and alkenyl/aryl (5q) combinations. Several heterocycle-derived Grignard reagents were successfully used $(5 \mathbf{r}-\mathbf{t})$. The preparative utility of the chemistry was demonstrated by a larger scale synthesis of sulfoxide $5 \mathbf{5}$; starting from $2.0 \mathrm{~g}$ of DABSO $(8.5 \mathrm{mmol})$ allowed sulfoxide $\mathbf{5} f$ to be isolated in $92 \%$ yield $(2.65 \mathrm{~g})$.

Next, we moved on to investigate whether the reaction was compatible with alternative organometallic reagents (Table 2). Entries 1 and 2 demonstrate the effective use of an alkyl or aryl Grignard reagent as the first nucleophile, partnered with an organolithium reagent as the second; in both cases the desired sulfoxides were obtained in good yields. Employing organolithium reagents as the first component, followed by Grignard reagents as the second, was also successful, providing good yields of sulfoxides (entries 3 and 4). Disappointingly, the use of organolithium reagents as both nucleophilic components 
Scheme 2. Scope of Sulfoxide Synthesis Employing Grignard Reagents, DABSO, and TMS- $\mathrm{Cl}^{a}$

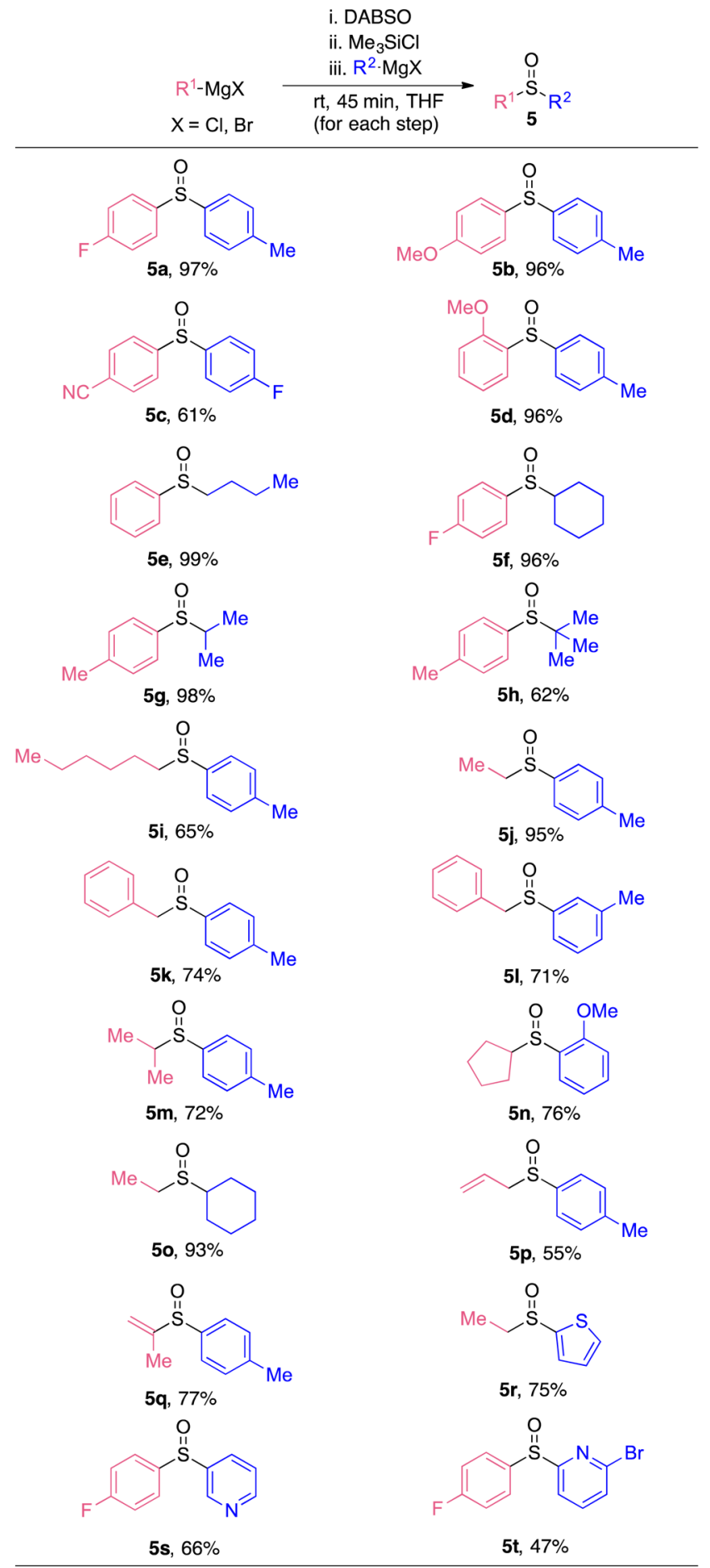

${ }^{a}$ Reaction conditions: $\mathrm{R}^{1}-\mathrm{MgX}$ (1.0 equiv), DABSO ( 0.5 equiv), TMSCl (1.50 equiv), $\mathrm{R}^{2}-\mathrm{MgX}$ ( 0.75 equiv), $0.33 \mathrm{M}$. Isolated yields.

only delivered the sulfoxide products in poor yields; a representative example is shown in entry 5 .

Our initial reaction design invokes the formation of an in situ generated silyl sulfinate ester (2, Scheme 1$)$. To investigate this hypothesis we attempted to isolate such a silyl sulfinate. Unfortunately, trimethylsilyl variants of sulfinate ester $\mathbf{2}$ were unstable; however, the corresponding dimethylphenylsilyl esters could be isolated in good yield. For example, silyl
Table 2. Sulfoxide Synthesis Employing Varied Organometallic Reagents ${ }^{a}$

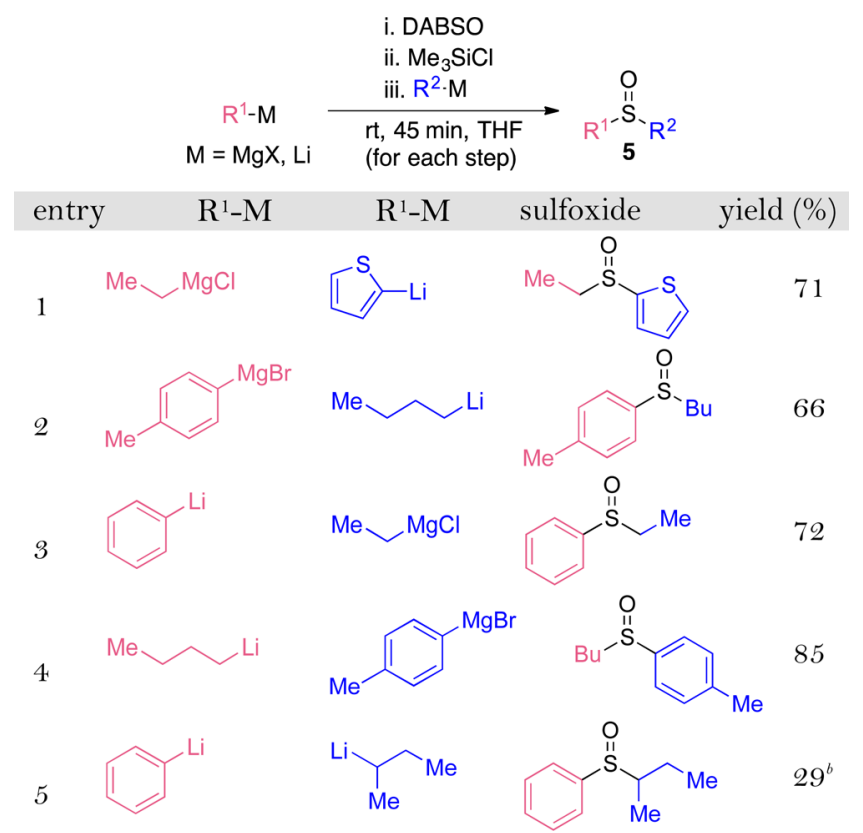

${ }^{a}$ Reaction conditions: $\mathrm{R}^{1}-\mathrm{M}$ (1.0 equiv), DABSO ( 0.5 equiv), TMSCl ( 1.50 equiv), $\mathrm{R}^{2}-\mathrm{M}$ ( 0.75 equiv) $0.33 \mathrm{M}$. Isolated yields. ${ }^{b} 1: 1$ mixture of diastereomers.

sulfinate 7 , generated from $4-\mathrm{F}-\mathrm{C}_{6} \mathrm{H}_{4}-\mathrm{MgBr}, \mathrm{DABSO}$, and $\mathrm{PhMe}_{2} \mathrm{Si}-\mathrm{Cl}$, was isolated in $99 \%$ yield (Scheme 3 ). Treatment

Scheme 3. Preparation of Silyl Sulfinate 7, and the Conversion of 7 into Sulfoxide $5 f$

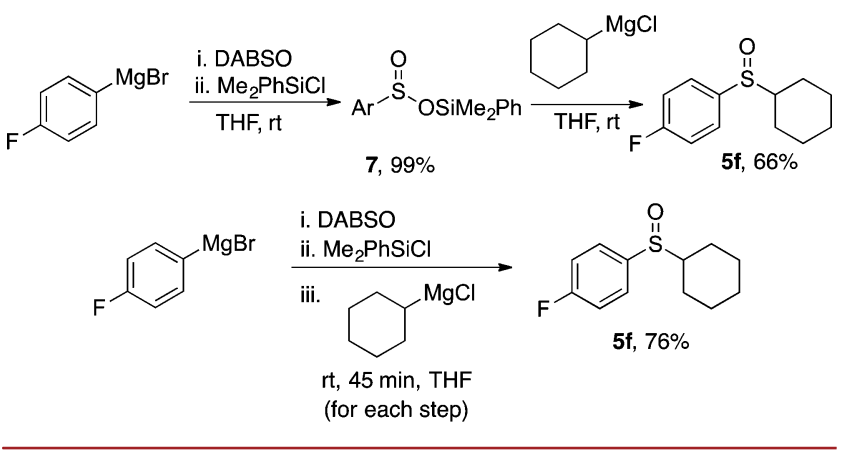

of silyl sulfinate 7 with cyclohexyl magnesium chloride delivered sulfoxide $\mathbf{5 f}$ in $66 \%$ yield, providing good support for the proposed reaction intermediate. A one-pot sequence employing $\mathrm{PhMe}_{2} \mathrm{Si}-\mathrm{Cl}$ in place of $\mathrm{Me}_{3} \mathrm{Si}-\mathrm{Cl}$ was also evaluated, and in this case sulfoxide 5f was obtained in $76 \%$ yield.

In conclusion, we have developed a general one-pot procedure for the preparation of sulfoxides from organometallic reagents, DABSO, and trimethylsilyl chloride. This protocol is applicable to commercially available and in situ generated Grignard and organolithium reagents, and combinations thereof. A wide variety of sulfoxides were obtained in good to excellent isolated yields. The use of room temperature conditions, short reaction times, and readily available starting materials is notable. 


\section{ASSOCIATED CONTENT}

\section{S Supporting Information}

The Supporting Information is available free of charge on the ACS Publications website at DOI: 10.1021/acs.orglett.6b00712.

Experimental procedures and full characterization for all compounds (PDF)

\section{AUTHOR INFORMATION}

\section{Corresponding Author}

*E-mail: michael.willis@chem.ox.ac.uk.

Notes

The authors declare no competing financial interest.

\section{ACKNOWLEDGMENTS}

We thank the Stichting Fundatie van de Vrijvrouwe van Renswoude and Stichting Nijmeegs Universiteits Fonds (SNUF, to D.C.L.), GlaxoSmithKline (to V.V.), and the EPSRC for support of this study.

\section{REFERENCES}

(1) (a) Legros, J.; Dehli, J. R.; Bolm, C. Adv. Synth. Catal. 2005, 347, 19. (b) Carreno, M. C. Chem. Rev. 1995, 95, 1717. (c) Bentley, R. Chem. Soc. Rev. 2005, 34, 609.

(2) World Health Organization, http://www.who.int/medicines/ publications/essentialmedicines/en/, retrieved on 03-03-2016.

(3) (a) Fernández, I.; Khiar, N. Chem. Rev. 2003, 103, 3651. (b) Mariz, R.; Luan, X.; Gatti, M.; Linden, A.; Dorta, R. J. Am. Chem. Soc. 2008, 130, 2172. (c) Mellah, M.; Voituriez, A.; Schulz, E. Chem. Rev. 2007, 107, 5133.

(4) Massa, A.; Acocella, M. R.; Sio, V. D.; Villano, R.; Scettri, A. Tetrahedron: Asymmetry 2009, 20, 202.

(5) (a) Evans, D. A.; Andrews, G. C.; Sims, C. L. J. Am. Chem. Soc. 1971, 93, 4956. (b) Fernández-Salas, J. A.; Eberhart, A. J.; Procter, D. J. J. Am. Chem. Soc. 2016, 138, 790. (c) Reich, H. J.; Jasperse, C. P.; Renga, J. M. J. Org. Chem. 1986, 51, 2981.

(6) For example: (a) Yoshimura, A.; Nguyen, K. C.; Klasen, S.; Saito, A.; Nemykin, V. N.; Zhdankin, V. V. Chem. Commun. 2015, 51, 7835. (b) Gu, X.; Li, X.; Chai, Y.; Yang, Q.; Li, P.; Yao, Y. Green Chem. 2013, 15, 357. (c) Boruah, J. J.; Das, S. P.; Ankireddy, S. R.; Gogoi, S. R.; Islam, N. S. Green Chem. 2013, 15, 2944. (d) Das, R.; Chakraborty, D. Synthesis 2011, 277. (e) Yoshimura, A.; Banek, C. T.; Yusubov, M. S.; Nemykin, V. N.; Zhdankin, V. V. J. Org. Chem. 2011, 76, 3812. (f) Kaczorowska, K.; Kolarska, Z.; Mitka, K.; Kowalski, P. Tetrahedron 2005, 61, 8315.

(7) (a) Wojaczyńska, E.; Wojaczyński, J. Chem. Rev. 2010, 110, 4303. (b) Andersen, K. K.; Gaffield, W.; Papanikolaou, N. E.; Foley, J. W.; Perkins, R. I. J. Am. Chem. Soc. 1964, 86, 5637.

(8) For a recent example of the synthesis of indole 3-sulfoxides, starting from sulfinic acids, see: Miao, T.; Li, P.; Zhang, Y.; Wang, L. Org. Lett. 2015, 17, 832.

(9) (a) Jia, T.; Bellomo, A.; Baina, K. E.; Dreher, S. D.; Walsh, P. J. J. Am. Chem. Soc. 2013, 135, 3740. (b) Jia, T.; Bellomo, A.; Montel, S.; Zhang, M.; El Baina, K.; Zheng, B.; Walsh, P. J. Angew. Chem., Int. Ed. 2014, 53, 260. (c) Jiang, H.; Jia, T.; Zhang, M.; Walsh, P. J. Org. Lett. 2016, 18, 972 .

(10) For recent examples: (a) Wei, J.; Sun, Z. Org. Lett. 2015, 17, 5396. (b) Murakami, K.; Yorimitsu, H.; Osuka, A. Bull. Chem. Soc. Jpn. 2013, 86, 1193.

(11) (a) Deeming, A. S.; Russell, C. J.; Hennessy, A. J.; Willis, M. C. Org. Lett. 2014, 16, 150. (b) Rocke, B. N.; Bahnck, K. B.; Herr, M.; Lavergne, S.; Mascitti, V.; Perreault, C.; Polivkova, J.; Shavnya, A. Org. Lett. 2014, 16, 154. (c) Chen, C. C.; Waser, J. Org. Lett. 2015, 17, 736.

(12) For recent reviews of $\mathrm{SO}_{2}$ chemistry, see: (a) Liu, G.; Fan, C.; Wu, J. Org. Biomol. Chem. 2015, 13, 1592. (b) Deeming, A. S.;
Emmett, E. J.; Richards-Taylor, C. S.; Willis, M. C. Synthesis 2014, 46, 2701.

(13) For a recent review of $\mathrm{SO}_{2}$ surrogates, see: Emmett, E. J.; Willis, M. C. Asian J. Org. Chem. 2015, 4, 602.

(14) For recent uses of DABSO, see: (a) An, Y.; Xia, H.; Wu, J. Org. Biomol. Chem. 2016, 14, 1665. (b) Tsai, A. S.; Curto, J. M.; Rocke, B. N.; Dechert-Schmitt, A.-M. R.; Ingle, G. K.; Mascitti, V. Org. Lett. 2016, 18, 508. (c) Deeming, A. S.; Russell, C. J.; Willis, M. C. Angew. Chem., Int. Ed. 2016, 55, 747. (d) Flegeau, F.; Harrison, J. M.; Willis, M. C. Synlett 2016, 27, 101. (e) Skillinghaug, B.; Rydfjord, J.; Odell, L. R. Tetrahedron Lett. 2016, 57, 533. (f) Deeming, A. S.; Russell, C. J.; Willis, M. C. Angew. Chem., Int. Ed. 2015, 54, 1168. (g) Emmett, E. J.; Hayter, B. R.; Willis, M. C. Angew. Chem., Int. Ed. 2014, 53, 10204. (h) Richards-Taylor, C. S.; Blakemore, D. C.; Willis, M. C. Chem. Sci. 2014, 5, 222. (i) Zheng, D.; An, Y.; Li, Z.; Wu, J. Angew. Chem., Int. Ed. 2014, 53, 2451. (j) Ye, S.; Wang, H.; Xiao, Q.; Ding, Q.; Wu, J. Adv. Synth. Catal. 2014, 356, 3225. (k) Wang, X.; Xue, L.; Wang, Z. Org. Lett. 2014, 16, 4056. (1) Emmett, E. J.; Hayter, B. R.; Willis, M. C. Angew. Chem., Int. Ed. 2013, 52, 12679. (m) Emmett, E. J.; RichardsTaylor, C. S.; Nguyen, B.; Garcia-Rubia, A.; Hayter, B. R.; Willis, M. C. Org. Biomol. Chem. 2012, 10, 4007. (n) Woolven, H.; GonzálezRodríguez, C.; Marco, I.; Thompson, A. L.; Willis, M. C. Org. Lett. 2011, 13, 4876. (o) Nguyen, B.; Emmett, E. J.; Willis, M. C. J. Am. Chem. Soc. 2010, 132, 16372.

(15) A number of preformed sulfinyl dications based on cyclic sulfamidites and cyclic sulfites are known. These have generally been employed in the stereoselective preparation of sulfoxides, usually via the sequential addition of organometallic reagents involving isolation of the first formed intermediate. For example, see: (a) Wudl, F.; Lee, T. B. K. J. Am. Chem. Soc. 1973, 95, 6349. (b) Rebiere, F.; Kagan, H. B. Tetrahedron Lett. 1989, 30, 3659.

(16) Kobayashi, M. Bull. Chem. Soc. Jpn. 1966, 39, 1296.

(17) (a) Bouchez, L. C.; Dubbaka, S. R.; Turks, M.; Vogel, P. J. Org. Chem. 2004, 69, 6413. (b) Bouchez, L. C.; Vogel, P. Synthesis 2002, 225.

(18) Stikute, A.; Peipinš̌, V.; Turks, M. Tetrahedron Lett. 2015, 56, 4578. 